\title{
Canto falado no samba e na bossa nova: um estudo de aspectos da relação entre texto e música
}

\author{
Gabriela Ricci (Universidade Estadual de Campinas, Campinas, São Paulo, Brasil) \\ gabricci@hotmail.com.
}

\begin{abstract}
Resumo: Este artigo apresenta desenvolvimento e resultados da pesquisa de mestrado Samba e bossa nova: um estudo de aspectos da relação texto-música. O objetivo da pesquisa foi buscar, em gravações de samba e de bossa nova, elementos linguísticos que caracterizassem o "canto falado", ou seja, o canto no limiar da fala, tendo como base teórica a fonologia prosódica. Selecionamos três canções de cada gênero, nas quais foram analisados: locais em que os intérpretes inseriram pausas em comparação com locais de segmentações fonológicas relevantes para o português brasileiro; acentuação lexical e sua relação com o acúmulo de acentos musicais - tom, duração e tempo métrico; alinhamento entre melodia, letra e rítmica do acompanhamento instrumental. Os resultados mostraram que os aspectos analisados relacionam-se de maneira a colaborar para a manutenção da prosódia do português brasileiro no canto popular.
\end{abstract}

Palavras-chave: Canto popular; Música popular; Música brasileira; Fonologia; Análise prosódica.

Spoken song in samba and in bossa nova: some aspects from the relationship between text and music

Abstract: This paper presents the development and the results from the master degree research Samba and Bossa Nova: a study of aspects of the music-text relationship. The aim of the research was search, in recordings of samba and Bossa Nova, linguistic elements that characterize the "spoken song", i.e., the singing at the threshold of speech, having as theoretical base the prosodic phonology. Three songs of each music style were selected so the following aspects could be analyzed: stops executed by singers in comparison with the phonological segmentations relevant to Brazilian Portuguese; lexical stress and its relationship with the accumulation of musical accents - pitch, duration and metric position; alignment between melody, lyrics and and rhythm of instrumental accompaniment. The results showed that the aspects analyzed are related in such a way as to contribute to the maintenance of Brazilian Portuguese prosody in popular singing.

Keywords: Popular singing; Popular Music; Brazilian Music; Phonology; Prosodic analysis.

\section{Introdução}

O trabalho com o canto popular brasileiro, seja em sua prática, seja na docência, evidencia a observação feita por Mário de Andrade (1972) sobre a relação estreita entre o canto popular do Brasil e a fala do português brasileiro. Dentre os diversos gêneros musicais praticados no Brasil, o samba e a bossa nova estão entre os que têm maior expressão internacional e ambos carregam como característica comum - entre outras - o "canto falado”, segundo a definição de Tatit (2008, p. 42), “o encontro de um lugar ideal para manobrar o canto na tangente da fala".

O objetivo deste artigo é apresentar os resultados obtidos na pesquisa de mestrado Samba e bossa nova: um estudo de aspectos da relação texto-música, que buscou entender como a relação de alguns aspectos musicais e linguísticos pode colaborar para a caracterização do "canto falado" nos dois estilos.

A hipótese levantada foi a de que ambos os estilos são constituídos com base na prosódia do português brasileiro. Para averiguá-la, investigamos i) a possibilidade de as pausas feitas pelos intérpretes coincidirem com locais de delimitação da frase fonológica e da frase entoacional, componentes fonológicos considerados importantes para o português brasileiro; ii) a incidência dos acentos musicais sobre as sílabas, considerando-se sua acentuação lexical; e iii) o papel do acompanhamento instrumental como reforço dessa acentuação. A fim de fundamentar essa relação, e levando em consideração o fato de as análises serem baseadas em gravações antigas e, portanto, com poucas possibilidades de manipulação ${ }^{1}$, fizemos uso da fonologia prosódica (NESPOR; VOGEL, 1986), exposta com mais detalhes adiante neste artigo. 
O samba e a bossa nova são estilos que carregam muitas características comuns e ambos têm sido estudados por diversos autores sob diferentes perspectivas. Uma das perspectivas abordadas, e que foi utilizada na pesquisa aqui exposta, é a que analisa suas características rítmicas.

Sandroni (2008) se utilizou da rítmica para traçar uma possível explicação para a origem do samba carioca. No início de seu trabalho, o autor mostra a construção do tresillo - ritmo constatado por musicólogos cubanos como característico das músicas de seu país - e como o seu desdobramento pode levar à síncope característica de vários dos estilos da música brasileira (ANDRADE, 1976, p. 279 apud SANDRONI, 2008, p. 20), também chamada de brasileirinho - formada por semicolcheia, colcheia e semicolcheia. A partir daí, o autor continua o desenvolvimento de sua proposta a partir da rítmica para chegar ao que ele chama paradigma do Estácio, que modifica o samba carioca a partir da década de 1930. Por meio de análises de melodias de sambas que o autor chama de estilo antigo - de 1917 a 1921 - e de sambas do estilo novo, sobretudo de compositores do Estácio e seus próximos - de 1927 a 1933 -, são levantadas características rítmicas que distinguem os dois tipos de samba, sobretudo o paradigma do Estácio, caracterizado pela antecipação do tempo forte, geralmente em uma semicolcheia, sobretudo na melodia. Sua análise de gravações de sambas de 1917 a 1933 levanta importantes aspectos do samba com relação ao canto, segundo Sandroni (2008, p. 202), “o ritmo contido na articulação silábica sugere o da batucada, e tanto quanto esta contribui para caracterizar o estilo novo".

Da mesma forma, Garcia (1999) mostra, por meio de análises de gravações feitas no primeiro disco de João Gilberto, o mentor e principal representante da bossa nova, características rítmicas desse estilo. Partindo da afirmação - não aceita por todos os estudiosos, mas interessante para a nossa análise - de Tinhorão (2013, p. 263) de que "a bossa nova [...] não constituiu um gênero de música, mas uma maneira de tocar”, podemos entender que o que ocorreu no final da década de 1950, do samba para a bossa nova, foi um fenômeno semelhante ao do final da década de 1920, do samba de estilo antigo para o samba de estilo novo. Garcia (1999, p. 106) analisa as alterações rítmicas feitas por João Gilberto, a partir do samba no violão, e detecta que "o compasso da batida de seu violão é binário como o do samba, mas seu padrão rítmico é executado em quatro tempos”, ou seja, em pares de dois compassos. Com relação à rítmica da voz, o autor mostra que João Gilberto mantém o padrão apresentado no paradigma do Estácio, mas, "sobreposta ao violão, sua voz é colocada ora em fase, ora em defasagem com os ataques aí percutidos” (GARCIA, 1999, p. 123).

A fonologia prosódica (NESPOR; VOGEL, 1986) segmenta o componente prosódico, ou seja, a fala, em constituintes hierarquizados, organizando-os da seguinte maneira, em ordem crescente: sílaba, pé métrico, palavra fonológica, grupo clítico, frase fonológica, frase entoacional e enunciado fonológico.

A sílaba, menor constituinte prosódico, apresenta um núcleo com o traço [mais forte], em português representado pela vogal, e adjacências com o traço [menos forte], representados no português pelas consoantes. O pé métrico é o constituinte prosódico exatamente acima da sílaba e estabelece relações de dominância entre as sílabas, na qual sempre uma é forte enquanto as demais devem ser fracas. A palavra fonológica é o constituinte que representa a interação entre o componente fonológico e o componente morfológico - não necessariamente a palavra fonológica será idêntica à palavra morfológica. O grupo clítico engloba somente uma palavra de conteúdo e os demais clíticos que a acompanham, como palavras funcionais e artigos. A frase fonológica é formada a partir de um núcleo formado por uma cabeça lexical e os clíticos em seu entorno, que não contenham palavras lexicais. A frase entoacional 
é formada por uma ou mais frases fonológicas e caracteriza-se por conter uma linha entoacional. De maneira geral, sua finalização tende a coincidir com as pausas na fala. O constituinte mais alto da hierarquia prosódica é o enunciado fonológico, formado por uma ou mais frases fonológicas e delimitado por um constituinte sintático e por proeminência relativa.

A fonologia prosódica tem sido usada por alguns autores como ferramenta para o estudo da relação canto-fala, como mostram os trabalhos descritos a seguir.

\subsection{Contribuiçõos entre música e fonologia}

Gelamo (2006) propõe um estudo sobre o samba-canção "Na batucada da vida", composto por Ary Barroso e Luis Peixoto em 1934, e interpretado por quatro cantoras de períodos diferentes: Carmen Miranda, Dircinha Batista, Elis Regina e Ná Ozzetti. Seu objetivo foi analisar como as intérpretes organizam e delimitam a frase entoacional, podendo criar, a partir daí, a "possibilidade de criação de diferentes efeitos de sentido para as interpretações" (GELAMO, 2006, p. 39). Os resultados fundamentam a ideia de que voz e linguagem não se separam e apontam para a possibilidade de haver uma influência mútua entre informações linguísticas e musicais. Um fator interessante encontrado por Gelamo é que as pausas não coincidentes com os limites da frase entoacional coincidiam, de alguma maneira, com locais que a autora denominou "conjunção rítmico-melódica", segundo ela, locais que apresentam um motivo rítmico musical. Esse trabalho serviu como base para a estruturação das análises segmentais e, apesar de não ser aprofundada e tampouco esclarecida, essa sugestão pelo motivo rítmico nos levou à busca por estudos mais concretos sobre a questão, contemplada no trabalho de Carmo Jr., descrito a seguir.

Carmo Jr. (2007) propõe, a partir da hierarquia prosódica de Nespor e Vogel (1986), uma hierarquia melódica, que organiza os componentes melódicos da seguinte maneira, em ordem crescente: glossema, nota musical, pé, célula, frase e período. Os glossemas são os elementos não segmentáveis e correspondem aos caracterizantes de duração - cronema -, intensidade - dinamema - e altura - tonema. A nota musical é o constituinte imediatamente superior aos glossemas. Acima da nota está o pé, que tem como núcleo uma nota com o traço [mais forte] e possíveis adjacentes com o traço [menos forte]. A célula vem logo acima do pé, contém um núcleo com os traços [mais forte] e [mais longo] e pode apresentar adjacências com os traços [menos forte] e/ou [menos longo]. Acima da célula está a frase musical, que toma as pausas como referência de segmentação e, segundo Carmo Jr. e Santos, é passível de ser associada à frase entoacional, de Nespor e Vogel (1986). O período, topo da hierarquia melódica, é composto por uma ou mais frases e inclui, além dos elementos supracitados, a cadência harmônica. Na análise da canção "Gabriela”, de Tom Jobim, Carmo Jr. e Santos (2010, p. 340) comparam a estrutura métrica dos componentes linguístico e melódico, mostrando que, "quando se instaura uma tensão, [...] o componente melódico domina o componente linguístico".

Nichols et al. (2009) pesquisaram a relação entre os acentos musicais e os acentos de letra em partituras de canções populares norte-americanas de diversos estilos, a fim de investigar a hipótese de que os compositores tendem a alinhar alguns elementos musicais da melodia com elementos do texto. Os autores consideraram os componentes musicais: posição métrica - forte ou fraco, com variações -, pico da melodia - com relação às notas vizinhas -, e duração relativa - com relação à média de duração das notas da música; e os componentes da letra: posição acentual da sílaba - acento primário, secundário ou não acentuada -, posição acentual das palavras gramaticais, e duração fonética das vogais - curta, longa ou ditongo. Os 
resultados corroboraram a hipótese, mostrando que sílabas mais acentuadas tendem a coincidir com posições métrico-musicais fortes, com os picos melódicos e as notas mais longas; palavras gramaticais (que carregam pouco peso semântico) tendem a coincidir com posições métrico-musicais fracas e são menos propensas a coincidir com os picos melódicos; e vogais tendem a manter a mesma relação de duração na melodia, se comparada à duração fonética.

\section{Metodologia}

O estudo quantitativo aqui apresentado foi estruturado a partir de uma análise piloto baseada nos estudos supracitados que, após diversas alterações, nos levou a alguns parâmetros consistentes para responder às questões levantadas.

Foram selecionadas para o estudo três canções de cada período. Para representar o samba, “Com que roupa?” (Noel Rosa), “Conversa de botequim” (Noel Rosa e Vadico) e "São coisas nossas" (Noel Rosa), todas interpretadas por Noel Rosa, um dos compositores reconhecidos por explorar de maneira marcante a coloquialidade nas letras de suas canções. Representando a bossa nova, "Chega de saudade” (Tom Jobim e Vinícius de Moraes), "Bim bom” (João Gilberto) e "Desafinado" (Tom Jobim e Newton Mendonça), todas interpretadas por João Gilberto, reconhecido por diversos autores como o criador da bossa nova.

As melodias das canções representantes do samba foram extraídas dos Songbooks Noel Rosa, vol. 1 e vol. 3, editados por Almir Chediak (1991a; 1991b). A base rítmica do acompanhamento dessas canções foi transcrita por esta autora e revisada pelo cavaquinista e violonista Eduardo Ferreira. As melodias das canções Chega de saudade e Desafinado foram extraídas dos Songbooks Bossa Nova vol. 2 e vol. 5, editados por Almir Chediak (1990a; 1990b). A melodia da canção "Bim bom" e a base rítmica de todas as canções representantes da bossa nova foram extraídas o livro Bim bom, de Walter Garcia (1999).

\subsection{Segmentações}

A escolha dos elementos fonológicos frase fonológica e frase entoacional se deu devido ao fato de eles serem considerados importantes para o entendimento da fala do português brasileiro (TENANI, 2002) porque organizam o contorno entoacional, delimitando as frases na fala. O uso da célula rítmica, por sua vez, se mostrou importante ao considerarmos os resultados observados por Gelamo (2006) sobre as pausas executadas em locais que a autora chamou de "conjunção rítmico-melódica” e que coincidem com as delimitações de células rítmicas, tal qual exposto por Carmo Jr. (2007).

Para realizar a marcação dos locais de delimitação da célula rítmica, foram seguidas as instruções dadas por Carmo Jr. (2007). Segundo o autor, a duração e a intensidade são os elementos determinantes da célula rítmica, enquanto a altura não o é. Na Figura 1, a seguir, é apresentado um trecho da canção "São coisas nossas", contendo os três elementos supracitados:

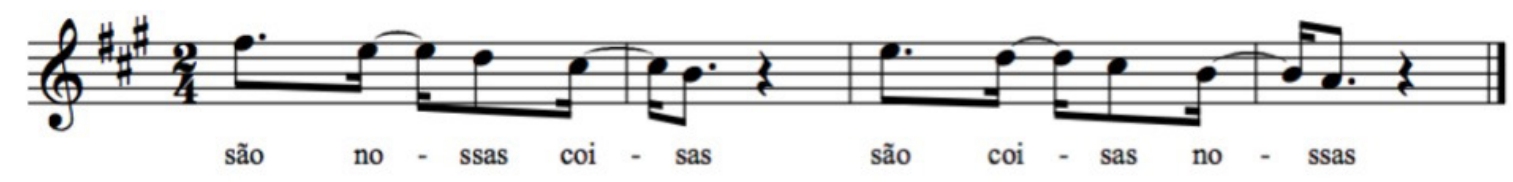

Figura 1: trecho da canção "São coisas nossas", contendo letra, altura, intensidade e ritmo Fonte: RICCI, 2015, p. 38. 
Se excluirmos a altura e mantivermos os outros elementos, chegamos a um padrão rítmico que explicita a célula rítmica tal qual explicada por Carmo Jr. Como mostra a Figura 2, desprovido de altura, o trecho exibe exatamente a mesma célula rítmica em /são nossas coisas/ e em /são coisas nossas/, configurando células rítmicas com núcleo na palavra/são/, que acumula os traços [mais forte] e [mais longo], e notas adjacentes, que contêm somente um desses traços.

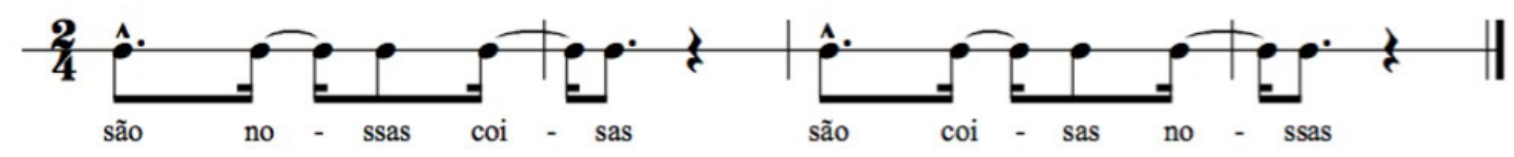

Figura 2: trecho da canção "São coisas nossas", contendo letra, intensidade e ritmo Fonte: RICCI, 2015, p. 39.

A frase fonológica é delimitada, conforme Nespor e Vogel (1986), considerando-se uma cabeça lexical (que pode ser um substantivo, um verbo, um advérbio ou um pronome) e todos os clíticos ao seu redor, até o próximo clítico que contenha uma cabeça lexical fora da projeção máxima da anterior. Segundo as autoras, a frase fonológica ainda pode apresentar uma reestruturação advinda da união de duas frases fonológicas, uma contendo a cabeça lexical e a outra portadora do complemento recursivo dessa cabeça lexical. A Figura 3 mostra a estruturação e a reestruturação de frase fonológica para a canção "Chega de saudade":

\section{[Se ela voltar] $\phi$ [que coisa] $\phi$ [linda] $\phi$ [que coisa] $\phi$ [louca] $\phi$}

[Se ela voltar] $\phi$ [que coisa linda] $\phi$ [que coisa louca] $\phi$

Figura 3: exemplo de reestruturação de frase fonológica com trecho da canção "Chega de saudade", no qual $\varnothing$ refere-se à frase fonológica

Fonte: RICCI, 2015, p. 33.

A delimitação da frase entoacional engloba as frases fonológicas ligadas ao nível mais alto da árvore sintática e, além dos elementos sintáticos, conta com fatores semânticos e de performance, como o estilo de locução. Segundo Nespor e Vogel (1986, p. 188, tradução minha), "a formulação da regra básica da frase entoacional é baseada na noção de que ela é o domínio de um contorno entoacional e que seu final coincide com as posições nas quais pausas seriam introduzidas na sentença”.

Considerando-se que a frase entoacional pode sofrer reestruturação, devido às já citadas diferenças de locução, podemos ter exemplos como o trecho de "Chega de saudade", exibido na Figura 4:

[Vai minha tristeza e diz a ela que sem ela não pode ser]

[Vai minha tristeza] [e diz a ela] [que sem ela não pode ser]

Figura 4: exemplo de construção e reestruturação de frase entoacional em trecho da canção "Chega de saudade" Fonte: RICCI, 2015, p. 35.

Pelo fato de as delimitações de frase entoacional poderem variar de acordo com o estilo de locução e a velocidade de fala, estas foram marcadas segundo o julgamento de sete juízes sobre as letras das canções. Para tanto, a letra de cada canção foi apresentada em parágrafo único, sem qualquer tipo de pontuação, para que os juízes lessem o texto pensando na maneira como ele seria falado e acrescentassem as pausas nos locais em que achassem devido. Consideramos as pausas que tiveram mais de 50\% de concordância entre os juízes. 
A segmentação na interpretação foi marcada a partir das pausas executadas pelos cantores, primeiramente de oitiva e posteriormente confirmadas em análise acústica.

\subsection{Marcação de acentos}

A sílaba foi a menor célula utilizada neste trabalho e, no caso das canções aqui analisadas, pode apresentar configurações diferentes com relação às notas da melodia, a saber: uma sílaba = uma nota; duas ou mais sílabas = uma nota. Nos casos em que duas ou mais sílabas = uma nota, foi considerada para a marcação de acentos musicais a sílaba que não se configurava como átona numa palavra. Na letra das canções foi marcada a acentuação lexical que, no português brasileiro, é caracterizada pelas sílabas tônicas com maior duração, se comparadas às sílabas átonas.

Na melodia das canções, foram marcados três tipos de acentuação, aos quais chamaremos acentos musicais: acento tonal, caracterizado pela nota mais alta (em Hz), se comparada às notas vizinhas; acento de duração, caracterizado pela nota mais longa (em ms), se comparada às notas vizinhas; e acento de posição métrica, caracterizado pelo tempo forte, em contraposição ao tempo fraco. "Cada uma dessas acentuações pode aparecer sozinha ou somada a outras. Quanto mais acentos uma mesma sílaba tiver, mais destaque ela terá naquela frase, configurando proeminência” (RICCI, 2015, p. 45).

A partir das comparações de segmentação e acentuação entre melodia e letra, buscamos entender quais parâmetros são mais relevantes para manter a prosódia do português brasileiro durante o canto.

\subsection{Alinhamentos}

A análise do alinhamento foi feita considerando-se somente a rítmica do acompanhamento, e não os outros elementos que o compõem, devido ao fato de que a rítmica é uma das grandes responsáveis pela caracterização dos estilos analisados (SANDRONI, 2008; GARCIA, 1999). As possibilidades de alinhamento utilizadas no trabalho levam em consideração melodia, letra e rítmica do acompanhamento - com exceção do bordão - e são relativas às posições métricas tempo forte regular, tempo forte sincopado, tempo fraco regular, tempo fraco sincopado ou, ainda, não alinhado. A Figura 5, abaixo, exemplifica os tipos de alinhamento:

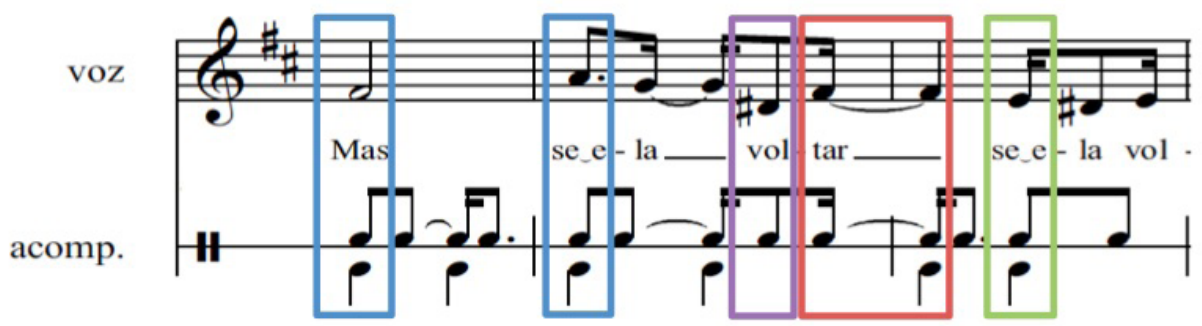

Figura 5: Exemplos de alinhamento entre melodia, letra e acompanhamento

Fonte: RICCI, 2015, p. 46.

As sílabas /mas/ e o primeiro/se_e/, demarcadas em azul, alinham-se com o acompanhamento em tempo forte regular; a sílaba/vol/, demarcada em lilás, está em tempo fraco sincopado; a sílaba /tar/, demarcada em vermelho, acontece em tempo forte sincopado; o segundo /se_e/, demarcado em verde, acontece em tempo fraco regular. As sílabas não demarcadas não se alinham com o acompanhamento.

Através da análise do alinhamento entre os três elementos que compõem a canção 
- melodia, letra e acompanhamento -, pretendemos observar o quanto este último elemento pode ou não reforçar a acentuação estabelecida pela voz.

\section{Resultados}

A comparação entre os três tipos de segmentação analisados neste trabalho - célula rítmica, frase fonológica e frase entoacional - e as pausas executadas pelos intérpretes trouxe, na maioria dos casos, resultados bastante similares entre o samba e a bossa nova. A Figura 6 mostra os dados obtidos para os três parâmetros, nos dois estilos:

\begin{tabular}{|c|c|c|}
\cline { 2 - 3 } \multicolumn{1}{c|}{} & Samba & Bossa nova \\
\hline Célula rítmica & $90 \%$ & $98 \%$ \\
\hline Frase fonológica & $96 \%$ & $88 \%$ \\
\hline Frase entoacional & $52 \%$ & $81 \%$ \\
\hline
\end{tabular}

Figura 6: Tabela mostrando a proporção de incidência das pausas executadas por Noel Rosa e por João Gilberto sobre os locais de delimitação das segmentações célula rítmica, frase fonológica e frase entoacional em cada uma das canções analisadas

Fonte: Elaborada pela autora (2017) .

As delimitações de célula rítmica e frase fonológica coincidiram com as pausas executadas por Noel Rosa e João Gilberto na grande maioria dos casos, enquanto a coincidência com a delimitação da frase entoacional teve uma variação alta de um estilo para outro - 52\% de coincidência no samba e $81 \%$ de coincidência na bossa nova. Uma possível explicação para o baixo índice de coincidência das pausas com a frase entoacional no samba pode ser o fato de que Noel Rosa utiliza um número elevado de pausas durante sua interpretação - 52 pausas em "Com que roupa?", 49 pausas em "Conversa de botequim” e 42 pausas em "São coisas nossas" -, enquanto João Gilberto utiliza um número bem menor de pausas - 17 pausas em "Chega de saudade", 9 pausas em "Bim bom” e 18 pausas em "Desafinado".

A comparação entre os acentos da melodia - acento tonal, de duração e de posição métrica - e o acento lexical mostrou o mesmo padrão para o samba e a bossa nova: uma tendência à maior incidência de acentos em notas da melodia que coincidem com as sílabas tônicas, se comparadas às átonas. A Figura 7 exibe a proporção de sílabas átonas (em vermelho) e sílabas tônicas (em azul) e sua relação com o acúmulo de acentos nas canções representantes do samba e da bossa nova.

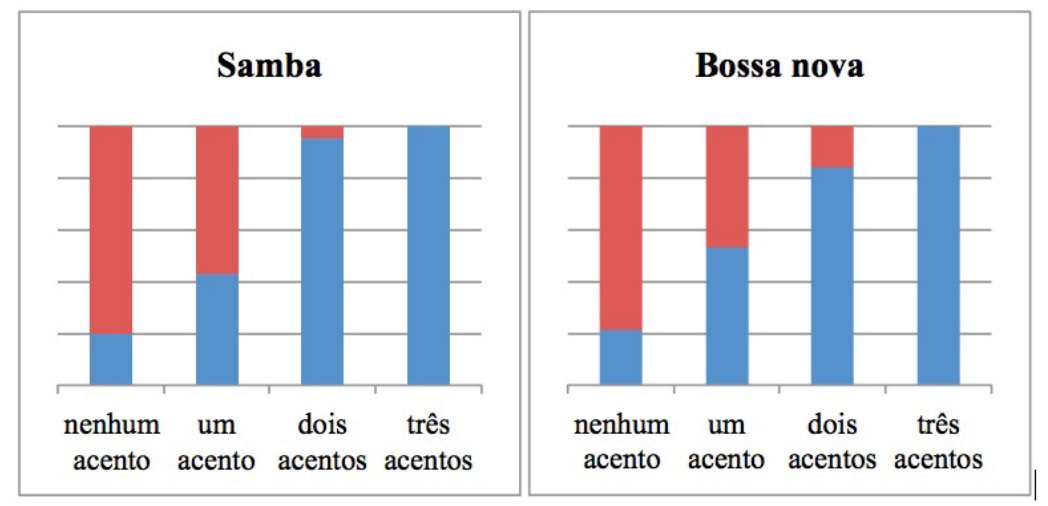

Figura 7: Proporção de sílabas átonas (em vermelho) e sílabas tônicas (em azul) com relação ao acúmulo de acentos por sílaba. À esquerda, dados relativos às canções representantes do samba; à direita, dados relativos às canções representantes da bossa nova

Fonte: Elaborada pela autora (2017). 
Vemos que a grande maioria das sílabas não acentuadas são átonas; as sílabas que contêm somente um acento são bem distribuídas entre tônicas e átonas; em oposição, a grande maioria das sílabas com dois acentos são tônicas. Já a totalidade das sílabas com três acentos também são tônicas em ambos os estilos.

A Figura 8, abaixo, mostra os dados relativos à proporção dos tipos de alinhamento entre melodia, letra e acompanhamento, a saber: em tempo forte regular (em azul), em tempo forte sincopado (em vermelho), em tempo fraco regular (em verde), em tempo fraco sincopado (em lilás) e não alinhado (em amarelo), conforme legenda na Figura.

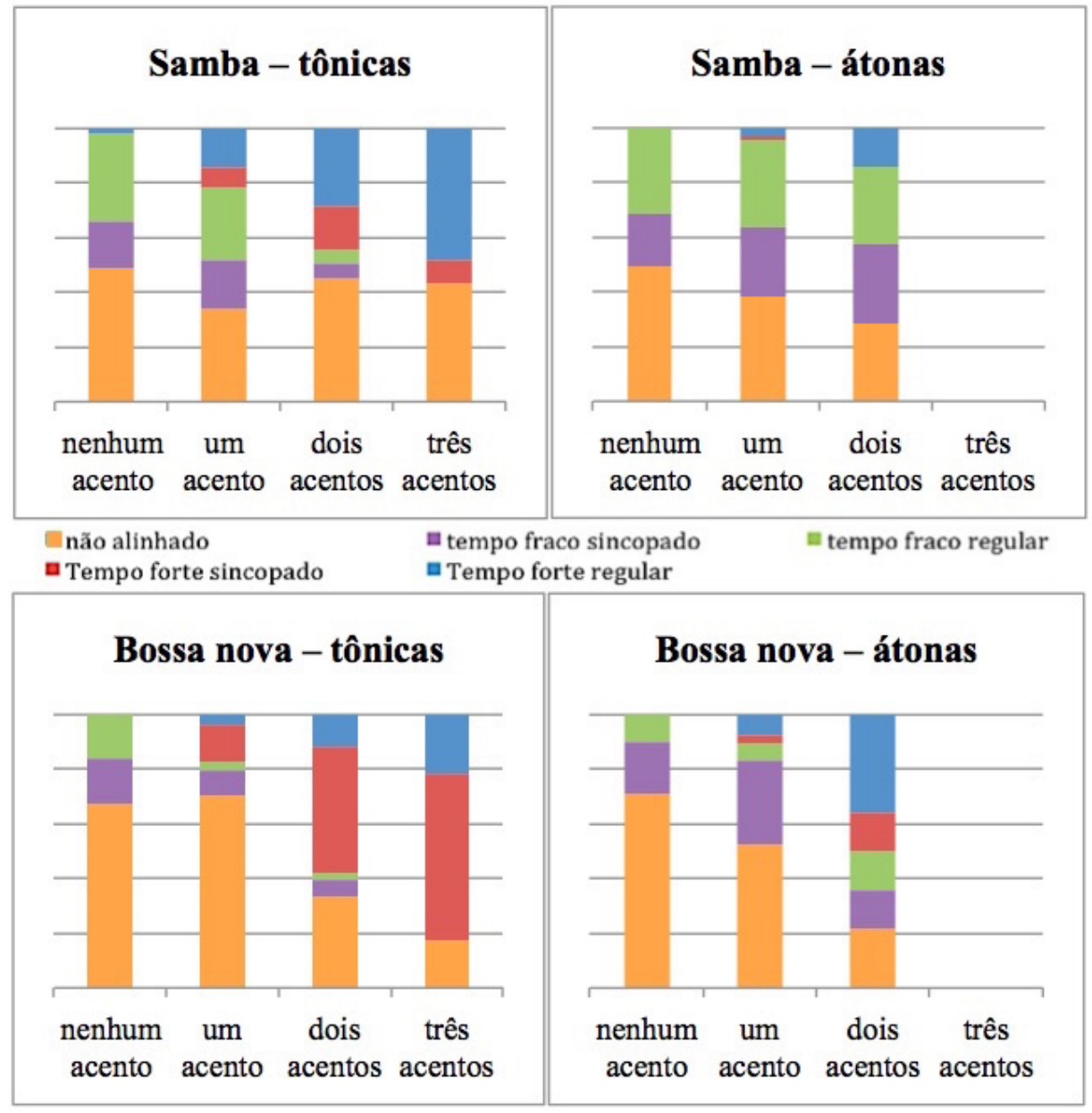

Figura 8: Proporção dos tipos de alinhamento em sílabas tônicas e átonas do samba e da bossa nova. Em cima, à esquerda, alinhamentos de sílabas tônicas e, à direita, de sílabas átonas do samba; embaixo, à esquerda, alinhamentos de sílabas tônicas e, à direita, de sílabas átonas da bossa nova

Fonte: elaborada pela autora (2017).

É possível observar que, de maneira geral, quanto mais acentos uma sílaba tem, maior é a sua tendência a se alinhar com o acompanhamento, seja em tempo fraco, seja em forte. Também é notável a maior ocorrência de sílabas tônicas alinhadas em tempo forte, tanto no samba quanto na bossa nova, sendo que todas as sílabas que acumulam três acentos, nos dois estilos, quando alinhadas, o são em tempo forte.

No samba, cerca de metade das sílabas que contêm um acento não estava alinhada com o acompanhamento, enquanto quase a totalidade das que se alinhavam estava em tempo fraco. A maioria das sílabas que continham acentos se alinhava, sendo que as tônicas mostram um índice maior de alinhamento em tempo forte quando as sílabas continham dois ou mais acentos. 
Na bossa nova, a maioria das sílabas não acentuadas ou que continham somente um acento não se alinhavam com o acompanhamento. Em oposição, a grande maioria das sílabas com dois ou três acentos alinhavam-se em tempo forte. Nas sílabas tônicas, vemos ainda um grande número de alinhamentos em tempo forte sincopado.

\section{Considerações finais}

Este artigo apresentou os resultados obtidos na pesquisa de mestrado Samba e bossa nova: um estudo de aspectos da relação texto-música, que teve como objetivo compreender a relação de alguns aspectos musicais e linguísticos e sua colaboração para a caracterização do "canto falado", ou o canto que está no limiar entre o canto e a fala.

Para averiguar a hipótese de que ambos os estilos são constituídos com base na prosódia do português brasileiro, investigamos três aspectos, selecionados a partir de análise piloto: i) as pausas executadas pelos intérpretes e sua relação com locais de delimitação de alguns componentes fonológicos considerados importantes para o português brasileiro; ii) os acentos musicais e sua relação com a acentuação lexical das sílabas; e iii) o papel do acompanhamento instrumental como reforço dessa acentuação.

As pausas executadas pelos intérpretes apresentaram alto índice de coincidência com os locais de delimitação da célula rítmica e da frase fonológica, tanto no samba quanto na bossa nova. A frase entoacional, por sua vez, apresenta um baixo índice de coincidência no samba - 52\% - e alto índice de coincidência na bossa nova - 81\%. Esse fenômeno ocorre devido ao número muito maior de pausas executadas por Noel Rosa, se compararmos às pausas executadas por João Gilberto. Se levarmos em consideração a ideia de bossa nova como uma maneira de tocar samba, e não um estilo em si, podemos sugerir que a preocupação com o ritmo era central para o samba da década de 1930, pois se tratava de um estilo musical em fase de estruturação. No caso da bossa nova, a preocupação com a maneira de dizer o texto pode ter um papel mais central, tendo em vista que ela já dispunha de uma estrutura rítmica de base bem estabelecida (a do samba).

A relação entre a acentuação lexical e a acentuação musical ocorreu conforme esperávamos, ou seja, há, em todas as canções analisadas, uma tendência à maior incidência de acentos musicais sobre sílabas tônicas, se comparadas às sílabas. Esse dado nos mostra que a acentuação musical reforça a acentuação lexical das palavras, colaborando para uma melhor inteligibilidade do texto.

A análise dos alinhamentos entre melodia, letra e rítmica do acompanhamento instrumental mostrou uma tendência de as sílabas mais proeminentes - com mais acentos musicais - se alinharem com o acompanhamento, sobretudo em tempo forte, com maior frequência, se compararmos às sílabas menos proeminentes - com menos acentos musicais -, que, quando se alinham, em geral o fazem em tempo fraco. Vimos também que a presença do alinhamento em tempo forte sincopado é muito superior na bossa nova do que no samba. Esse fato pode ser explicado pela construção rítmica dos dois estilos, uma vez que o acompanhamento da bossa nova é organizado em pares de dois compassos, o segundo iniciando-se quase sempre em tempo sincopado, enquanto o acompanhamento do samba é organizado em compassos avulsos, iniciando-se quase sempre em tempo regular.

O tamanho reduzido do corpus não nos permite fazer generalizações a respeito dos resultados encontrados neste trabalho. Para tanto, faz-se necessária a análise de um número maior de músicas, que contemple uma gama também maior de estilos, inclusive aqueles que não utilizam o "canto falado", como o samba-canção ou o bolero. Apesar disso, uma maior compreensão sobre os componentes musicais e linguísticos que agem em prol da in- 
teligibilidade do texto e, mais especificamente, do "canto falado" pode ser de grande valia tanto para a prática quanto para a docência do canto popular brasileiro.

\section{Notas}

1 Alguns estudos sobre música utilizam-se da fonologia acústica, que analisa sinais acústicos da fala ou do canto. No caso desta pesquisa, esse tipo de análise seria possível, mas a manipulação dos áudios para isolar a voz do restante dos instrumentos levaria a uma perda de qualidade no sinal sonoro, o que dificultaria as análises acústicas, prejudicando, consequentemente, seus resultados.

2 Ao longo deste trabalho, sempre que nos referirmos ao samba estaremos tratando da vertente carioca do estilo.

3 O samba do Estácio é aquele feito pelo grupo de compositores do bairro Estácio de Sá, no Rio de Janeiro.

4 Cf. Máximo (1990).

5 Cf. Tinhorão (2013), Tatit (2008) e Garcia (1999).

6 A rítmica dos acompanhamentos transcritos nas figuras ao longo do artigo é composta por duas linhas: a de cima exibe a rítmica das notas agudas, tocadas nas cordas finas do violão ou por instrumentos médio/agudos, como cavaquinho ou tamborim, por exemplo; a de baixo exibe a rítmica do bordão, ou seja, das notas graves, emitidas pelas cordas grossas do violão ou instrumentos como o trombone ou o surdo, por exemplo.

7 "The formulation of the basic intonational phrase formation rule is based on the notions that the intonational phrase is the domain of an intonational contour and that the ends of intonational phrases coincide with the positions in which pauses may be introduced in a sentence” (NESPOR; VOGEL, 1986, p. 188)

8 Por meio do software livre praat, disponível em <www.praat.org $>$.

9 Apesar disso, análises contendo outros aspectos do acompanhamento, como harmonia e timbres, enriqueceriam nossos resultados.

\section{Referências}

ANDRADE, Mário de. Ensaio sobre a música brasileira. 3. ed. São Paulo: INL, 1972.

Música, doce música. In: SANDRONI, Carlos. Feitiço decente: transformações do samba no Rio de Janeiro, 1917-1933. 2. ed. Rio de Janeiro: Jorge Zahar Editor: Editora UFRJ, 2008.

BARBOSA, Plínio Almeida.; ERIKSSON, Anders; AKESSON, Joel. On the robustness of some acoustic parameters for signalling word stress across styles in Brazilian Portuguese. Interspeech. Proceedings of Interspeech, Lion, France, 2013. p. 282-286.

CARMO JR., José Roberto do. Melodia e prosódia: um modelo para a interface música-fala com base no estudo comparado do aparelho fonador e dos instrumentos musicais reais e virtuais. 2007. $192 \mathrm{f}$. Tese (Doutorado em Linguística) - Faculdade de Filosofia, Letras e Ciências Humanas, Universidade de São Paulo, São Paulo, 2007.

CARMO JR., José Roberto do; SANTOS, Raquel Santana. Hierarquia prosódica e hierarquia melódica na canção Gabriela. DELTA, v. 26, n. 2, p. 319-343, 2010.

CHEDIAK, Almir (Ed.). Bossa nova. Rio de Janeiro: Lumiar, 1990a. v. 2.

Bossa nova. Rio de Janeiro: Lumiar, 1990b. v. 5.

Noel Rosa. Rio de Janeiro: Lumiar, 1991a. v. 1.

Noel Rosa. Rio de Janeiro: Lumiar, 1991b. v. 3.

GARCIA, Walter. Bim bom: a contradição sem conflitos de João Gilberto. São Paulo: Paz e Terra, 1999.

GELAMO, Renata Pelloso. Organização prosódica e interpretação de canções: a frase entoacional em quatro diferentes interpretações de na batucada da vida. 2006. 107 f. Dissertação (Mestrado em Estudos Linguísticos) - Instituto de Biociências, Letras e Ciências Exatas, Universidade Estadual Paulista, São José do Rio Preto, 2006. 
GILBERTO, João. Bim bom, Chega de saudade (itálico). João Gilberto (intérprete, voz). Rio de Janeiro: Odeon, 1959. Disco Long Play.

JOBIM, Tom; MENDONÇA, Newton. Desafinado, Chega de saudade (itálico). João Gilberto (intérprete, voz). Rio de Janeiro: Odeon, 1959. Disco Long Play.

JOBIM, Tom; MENDONÇA, Newton. Desafinado, Chega de saudade (itálico). João Gilberto (intérprete, voz). Rio de Janeiro: Odeon, 1959. Disco Long Play.

MÁXIMO, João. Noel Rosa: uma biografia. Brasília: UNB/Linha Gráfica Editora, 1990.

NESPOR, Marina; VOGEL, Irene. Prosodic phonology. Dordrecht, Netherland: Foris publications, 1986.

NICHOLS, Eric; MORRIS, Dan; BASU, Sumit; RAPHAEL, Christopher. Relationships between lyrics and melody in popular music. In: INTERNATIONAL SOCIETY FOR MUSIC INFORMATION RETRIEVAL CONFERENCE, 10. Proceedings of the 10th International Society for Music Information Retrieval Conference. Kobe, Japan: 2009. p. 471-476.

RICCI, Gabriela. Samba e bossa nova: um estudo de aspectos da relação texto-música. 2015. 119 f. Dissertação (Mestrado em Linguística) - Instituto de Estudos da Linguagem, Universidade Estadual de Campinas, Campinas, 2015.

ROSA, Noel. Com que roupa? (itálico). Noel Rosa (Intérprete, voz). Rio de Janeiro: Parlophon, 1931. Disco $78 \mathrm{rpm}$.

ROSA, Noel; VADICO. Conversa de botequim. Noel Rosa (Intérprete, voz). Rio de Janeiro: Odeon, 1935. Disco 78 rpm.

ROSA, Noel. São coisas nossas. Noel Rosa (Intérprete, voz). Rio de Janeiro: Columbia, 1932. Disco $78 \mathrm{rpm}$.

SANDRONI, Carlos. Feitiço decente: transformações no samba do Rio de Janeiro, 1917-1933. 2 ed. Rio de Janeiro: Jorge Zahar Editor: Editora URFJ, 2008.

TATIT, Luiz. O século da canção. 2. ed. São Paulo: Ateliê editorial, 2008.

TENANI, Luciani Ester. Domínios prosódicos no português do Brasil: implicações para a prosódia e para a aplicação de processos fonológicos. 2002. $331 \mathrm{f}$. Tese (Doutorado em Linguística) - Instituto de Estudos da Linguagem, Universidade Estadual de Campinas, Campinas, 2002.

TINHORÃO, José Ramos. Pequena história da música popular: segundo seus gêneros. 7. ed. São Paulo: Editora 34, 2013.

Gabriela Ricci - Bacharela em Música com ênfase em Canto Popular. Mestra em Linguística pela Universidade Estadual de Campinas. Atuou como professora substituta no Departamento de Educação Musical da Universidade Federal da Paraíba, no qual ministrou diversas disciplinas ligadas à Música Popular. 